\title{
EL CONTEXTO Y LA OBRA DE VOLOSHINOV -LAS CONTROVERSIAS IDEOLÓGICAS- CASI UN SIGLO DESPUÉS
}

Sobre Inna Tylkowski. Voloshinov en contexte. Essai d'épistémologie historique [Voloshinov en contexto. Ensayo de epistemología histórica]. Limoges: Lambert-Lucas, 2012. 377 pp.

Dora Riestra

GEISE

Universidad Nacional de Río Negro

El libro de Inna Tylkowski, publicado en 2012, lamentablemente no ha sido traducido al español aún, a pesar de que su aporte es imprescindible para investigadores en Lingüística, en Comunicación social, en Sociología, en Filosofía y en Historia de las Ciencias del lenguaje en general.

Basada en su tesis doctoral, que dirigiera Patrick Sériot en la Universidad de Lausanne, Suiza, esta lingüista rusa realiza un análisis minucioso del contexto socio-histórico (entre 1890 y 1930) de Valentin Voloshinov, época en la que transcurre la vida del autor estudiado. Abarca las producciones lingüísticas, filosóficas, psicológicas y sociológicas, todas las vertientes que confluyen en la obra Marxismo y filosofía del lenguaje, la tesis doctoral que Voloshinov elaboró durante tres años y que fuera publicada en 1929.

El análisis de Tylkowski en Voloshinov en contexto. Ensayo de epistemología histórica consistió en una búsqueda de relaciones conceptuales entre los autores rusos y occidentales citados en la obra de Voloshinov, complementándolo con la 
interpretación afinada de las nociones específicas del autor y sus desarrollos conceptuales rastreados a lo largo de la obra.

Pese a la distancia generacional, casi cien años después de la recepción del autor en la Rusia posrevolucionaria, la obra es contextualizada y dimensionada a la manera de un contemporáneo. De este modo, la principal obra de Voloshinov es revisitada desde la interdisciplinariedad, en función de mostrar la relación intertextual basada en la intratextualización. El trabajo ofrece respuestas de carácter teórico e histórico a la vez, como puntos de partida para continuar la investigación programática del autor estudiado. En este sentido puede destacarse que el marxismo de los autores rusos de la época apuntaba a poner en práctica tanto el enfoque materialista dialéctico de los problemas, como el método elaborado para abordarlos; se trata de una concepción del marxismo que tiene más proximidad con la de los latinoamericanos de los años 70 del siglo pasado, que con el marxismo estructuralista de la Europa de posguerra, particularmente la concepción marxista francesa de esa época.

El libro de esta lingüista rusa nos ofrece la posibilidad de reflexionar sobre la metodología en las ciencias sociales y la revisión epistemológica que, cuidadosamente, se presenta como ensayo. Estimula la investigación de nociones como "ideología, reflejo y refracción", con los valores semióticos, sociales y cotidianos que se atribuyen a la cosmovisión de Voloshinov. Dicho de otro modo, las ideas lingüísticas, psicológicas y sociológicas son delimitadas y contextualizadas en un trabajo filológico que apunta a reponer la concepción filosófica marxista de Voloshinov.

La concepción de la "interacción verbal" (con las influencias rusas de interacción interindividual, recibidas de Sorokin) en relación con la de "diálogo" (con la influencia de Jakubinskij) y 
la noción de la "naturaleza social del enunciado" (con la influencia sociológica de Roberty) conforman una construcción teórica compleja.

La síntesis teórica de Voloshinov en Marxismo y Filosofía del lenguaje es analizada en su carácter semiológico, con la incorporación de la noción de ideología en su aspecto clásico (concebido después de Marx en occidente), agregando a su significado el aspecto -hoy considerado así- cultural, lo que muestra el carácter anticipatorio del concepto voloshinoviano de "signo ideológico". La autora sostiene en la p. 252:

Por supuesto, la noción de signo en la concepción de Voloshinov es más amplia que la de signo verbal. Por signo, Voloshinov designa todo producto socio-cultural (o ideológico), incluyendo la Palabra. [Traducción nuestra]

La posición materialista dialéctica de Voloshinov en el contexto soviético de los años veinte, en lo que respecta a la psicología, se enmarca en las discusiones acerca de las relaciones entre pensamiento y lenguaje como problema de la conciencia, lo que ya era objeto de estudio interdisciplinar en las ciencias humanas. En este sentido, las ideas freudianas del inconsciente no podían ser consideradas más que una concepción poco consistente; puesto que, para los rusos marxistas, la conciencia, de carácter verbal y social, se concebía como un dominio semiótico objetivo, muy próximo a lo conceptualizado por Vygotski en la misma época, con quien, según la autora, Voloshinov compartía la concepción de lenguaje y psiquismo, por la referencia explícita al psicólogo en sus textos. Dice Tylkowski que la crítica al freudismo

(...) no constituye un fin en sí misma. Representa un punto de partida para su elaboración de su concepción de la conciencia. La conciencia coincide para él con el psiquismo. De carácter verbal, semiótico, la conciencia es un fenómeno objetivo, accesible al análisis. (p. 253) 
Esta posición, asumida en pleno contexto de reflexología y behaviorismo, implica introducir un nuevo objeto de estudio: la conciencia en el dominio de la psicología.

Es interesante resaltar las dos influencias respecto de los determinismos sociales que la autora atribuye a dos fuentes: por un lado, al materialismo ruso de Plejánov, Bujarin y, por otro, a la sociología de Roberty, desde una posición no marxista, autodenominada neopositivista. En este sentido, Tylkowski señala que en Voloshinov no hay una ruptura entre la sociología burguesa y la marxista. De allí surge la noción de interacción social principalmente verbal, definida como diálogo; concepto que corresponde al hecho social elemental que formulara Sorokin entre dos individuos como "mediadores" con el lenguaje, el que, además de Voloshinov, tomará Jakubinskij para desarrollar las teorías del diálogo. Para entender este concepto, la autora remite al Instituto de la palabra viva ${ }^{1}$ y explica que Voloshinov no se detuvo en este concepto del diálogo, sino que exploró su elemento constitutivo, el "enunciado", así como las estructuras sintácticas en que éste se realiza. Es decir, estudió los hechos psíquicos (la conciencia), el lenguaje, el enunciado, las estructuras sintácticas, en tanto elementos constitutivos del intercambio verbal y social. Destaca de este modo la anticipación del autor frente a conceptos que los intelectuales rusos abordarían posteriormente, como es el de "interacción social".

El método de esta investigación tiene la singularidad de poner en evidencia tanto las influencias conceptuales (trabajo

${ }^{1}$ Ver Irina Ivanova: Le rôle de l'Institut Zivogo Slova (Petrograd) dans la culture russe du debut du XXe Siècle, en Langage et pensé: Union Sovietique annés 1920-1930. Cabiers de l'ILSL, $\mathrm{N}^{\circ} 24$, Lausanne, 2008. Se trata de la descripción de este instituto que consistió en la creación de campos de estudios interdisciplinarios entre las ciencias y las artes en los años 1918- 1924, en el auge de la revolución bolchevique. 
filológico), como los datos contextuales o, como la autora lo denomina, el "macrocontexto" de la obra de Voloshinov.

En definitiva, la lingüista rusa quiso mostrar el sistema de pensamiento de Voloshinov, por lo que considera que no es indispensable ni necesario poner en relación al autor estudiado con las obras de Bajtín y Medvedev, así como las disputas de autorías, ni la cuestión del llamado "Círculo de Bajtín", históricamente inexistente, lo que Tylkowski denomina el "microcontexto" de la obra de Voloshinov.

Encierra sus conclusiones con una afirmación muy contundente frente a las controversias autorales de los intelectuales rusos que se divulgaran tardíamente en occidente:

la relación directa entre la conciencia individual y la cultura (la "ideología"), la puesta en evidencia del contenido social de la conciencia, el enfoque semiótico y comunicativo, la comprensión de una obra literaria (de un "enunciado") como hecho social (o sociológico), la importancia de la metodología sociológica (marxista) en análisis literario, el recurrir a las nociones de "diálogo" (de interacción socioverbal) y de "socialidad" con un rol de primer plano en la constitución de la conciencia y en la creación sociocultrural (ideológica) no sólo están presentes en los textos del "grupo BMV" (Bajtín, Medvedev, Voloshinov), ni del "Círculo Bajtín", sino también en los textos de Sakulin, Spet, Roberty, Sarukin, Jakubinskij. Estos últimos no forman parte del "grupo BMV", ni del "Círculo Bajtín". Sus textos no fueron atribuidos a Bajtín apelando a la presencia de tales ideas. ¿Es necesario poner en relación directa las concepciones de Bajtín, Medvedev y Voloshinov? La respuesta es no. (p. 256)

Con este argumento, Tylkowski nos propone que, en lugar de buscar paralelismo, sería más productivo para el mundo académico reconstruir los contextos intelectuales de los autores 
de los textos controversiales (Bajtín y Medvedev), lo que permitiría, metodológicamente, poner en evidencia las particularidades de las formulaciones de cada uno, a la manera en que fue hecho en esta obra.

Las 50 páginas de anexos de Voloshinov en contexto. Ensayo de epistemología histórica dan cuenta de las fuentes consultadas y constituyen el material original de los textos citados en el ensayo.

El carácter didáctico de este libro es un aporte valioso, puesto que la traducción ha sido realizada por una lingüista rusa que domina el francés, quien dio cuenta del contexto original de la obra de Voloshinov y dirige su texto a los lectores de occidente, con el cuidadoso trabajo de traducción lingüístico-cultural.

Al definirlo como estudio de epistemología histórica, creemos que los jóvenes investigadores en las Ciencias de la cultura/Ciencias humanas-sociales cuentan con una herramienta metodológica que trasciende un estudio filológico tradicional, un desafío teórico de nuestro tiempo frente a las vicisitudes políticas y culturales que nos interpelan. 